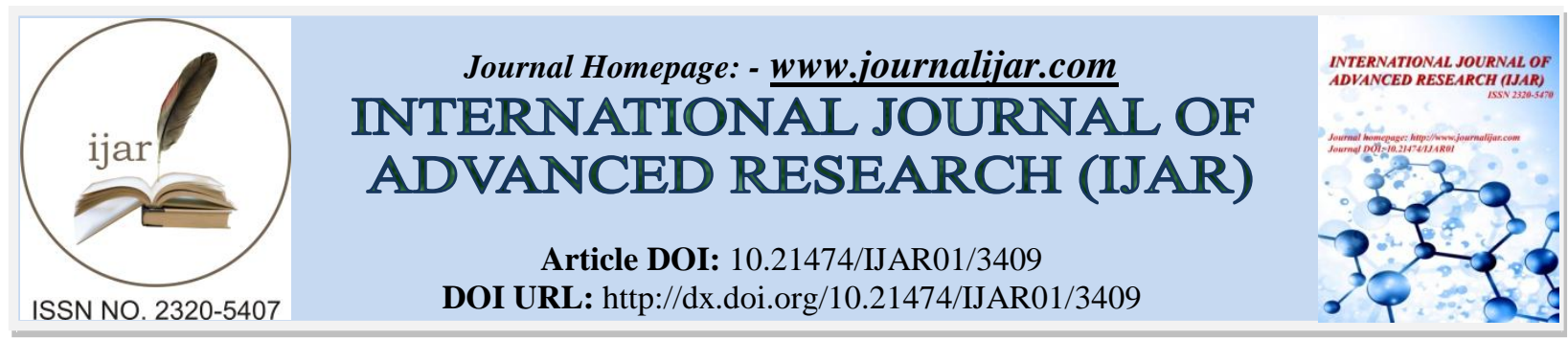

RESEARCH ARTICLE

\title{
APLASTIC CRISIS CAUSED BY PARVOVIRUS B19 IN AN ADULT PATIENT WITH SICKLE-CELL DISEASE.
}

Mashaiel Al Hajri MD, Israa Alaithan MD, Mona Al Hammad MD and Wejdan Al Omran MD.

\section{Manuscript Info}

Manuscript History

Received: 13 December 2016

Final Accepted: 23 January 2017

Published: February 2017

\begin{abstract}
We describe a case of aplastic crisis caused by parvovirus B19 in an adult sickle-cell patient presenting with Fever, abdominal pain and headache. Reticulocytopenia in patients with Sickle-cell disease suggests B19 infection where Anti-B19 IgM and IgG were detected
\end{abstract}

Copy Right, IJAR, 2017,. All rights reserved.

\section{Introduction: -}

Parvovirus B19 is a small single stranded DNA virus that infects and replicates in erythroid progenitor cells of the bone marrow and blood, leading to inhibition of erythropoiesis ${ }^{[1]}$. It causes aplastic crisis by inhibiting erythroid series formation through the pathogen's direct cytotoxic effect on erythroid burst and colony forming units. B19 commonly infects rapidly dividing cells such as bone marrow or developing fetal tissues ${ }^{[2]}$. It is now recognized as an important human pathogen causing transient aplastic crisis (TAC) in chronic hemolytic anemia patients. This clinical presentation is related to the tropism of the virus for bone marrow precursors, mainly erythroblasts ${ }^{[1]}$. During an acute infection, this results in a significant drop in hematocrit. In healthy individuals, RBC production returns in 10 to 14 days. However, in individuals with an increased RBC turnover, even a limited cessation of RBC production can lead to a clinically significant drop in hemoglobin and transient aplastic crisis (TAC) ${ }^{[3]}$. Severe anemia is most likely to occur in individuals with underlying hemolytic anemia (e.g. sickle cell disease, hereditary spherocytosis) ${ }^{[4]}$.

\section{Case Report: -}

A nineteen years old Saudi female from Al-Khobar and living there. Admitted to the KFHU through ER when she was complaining of abdominal pain and fever for 5 days duration.

The patient is a known case of sickle cell disease and G6PD deficiency since childhood. She was on folic acid 1 tablet/day. The patient gave history of recurrent attacks of Vaso-occlusive painful crisis (VOC) for more than 12 times per year since childhood, which decreased 1-2 attacks per year during the last 4 years. The attacks were precipitated by cold and stress and it were managed in the ER with analgesic and IV fluids. Also, she has a history of recurrent admission to the hospital 1-2 times per year. Last admission was one year back. There is no previous history of ICU admission. She had blood transfusion when she was 10 years old. No history of previous surgery.

Six days prior to the presentation, the patient started to have fever that was about $38.1 \mathrm{C}^{\circ}$, which associated with chills and headache. Also, the patient gave a history of watery diarrhea 3 to 4 times per day not associated with blood or mucus. There was no chest pain, shortness of breath, palpitations, sweating, or meningeal signs. She sought medical advice in a private hospital where blood investigations were done. She had been managed by Paracetamol and antibiotics where the fever subsided. 
Three days later she started to have acute progressive continuous right hypochondrial pain not related to food or specific position, localized not radiating to other site. The pain was associated with nausea and vomiting moderate amount with no hematemesis or diarrhea. No history of similar symptoms in the family. She went to the ER where she was managed by IV fluid and analgesia.

At the day of presentation she came to the ER complaining of worsening of the abdominal pain not associated with nausea or vomiting.

\section{Physical Examination: -}

Physical examination reveals a well-developed, alert, and oriented woman in pain. Her blood pressure was $110 \backslash 70$ $\mathrm{mmHg}$, pulse $110 \mathrm{bpm}$, respiratory rate was $20 \mathrm{bpm}$ and temperature was $37.7^{\circ} \mathrm{C}$. The patient had pale conjunctiva without jaundice. Chest examination is normal EAEB. Cardiac examination shows normal S1, S2 with grade III/VI systolic murmur at pulmonary area. Abdominal examination reveals soft and lax abdomen with mild tenderness in the right hypochondrial area and no hepatosplenomegaly.

Laboratory evaluation was performed on admission to the hospital. The patient's hemoglobin was $3.9 \mathrm{~g} / \mathrm{dL}$, the hematocrit was $11.1 \%$, RBC was 1.2 , platelet count was 148 , reticulocyte $1.9 \%$, and the leukocyte count was normal. Results of blood chemistry, urinalysis, chest radiography and abdominal ultrasound were normal.

\section{Management:-}

On admission, the patient was treated with oral analgesics and IV fluids. After obtaining the blood cultures, IV antibiotic therapy was started. Also the patient is transfused with 3 units of packed RBC. Her hemoglobin increased to $8.3 \mathrm{~g} / \mathrm{dL}$. Acute parvovirus B19 infection is suspected and confirmed by B19-specific serology that reveals an IgM value of $86.27 \mathrm{u} \backslash \mathrm{ml}$ (positive value >11) and IgG of $21.93 \mathrm{u} \backslash \mathrm{ml}$ (positive value $>11 \mathrm{u} \backslash \mathrm{ml}$ ). The patient's pain and fever resolve by the $2^{\text {nd }}$ day of admission. She had been discharged on $4^{\text {th }}$ day of admission afebrile with no headache or pain on antibiotic.

\section{Discussion: -}

Parvovirus B19 commonly infects rapidly dividing cells such as bone marrow or developing fetal tissues. Infection is most frequently found in the late winter or early spring. As parvovirus DNA has been found in respiratory secretions at the time of viremia, the most common route of transmission appears to be respiratory ${ }^{[5]}$.

Here we describe parvovirus infection in an adult with sickle cell anemia. After reviewing the literature and reported cases, we found that usually the infection occur during childhood or early adolescence. The peak incidence rates occur in 6 to 14-year-old ${ }^{[5]}$, but rarely during adulthood. Parvovirus infection causes transient aplastic crisis in patients with hemolytic anemia such as sickle cell anemia, hereditary spherocytosis and thalassemia. Clinical presentation may vary depending on the extent of the infection. Usually they present with sever symptomatic anemia secondary to the massive drop in hemoglobin level. Other presentation could be due to drop in leucocytes count or platelet count. In the case we described here the patient presented with vague symptoms such as abdominal pain, fatigue and symptomatic anemia. Upon laboratory investigations a drop on hemoglobin level with accompanying reticulocytopenia will raise the suspicion of parvovirus infection in those patients, other cell linage might be affected too, inducing leucopenia or thrombocytopenia.

Serum IgM testing is recommended to diagnose acute viral infection in immunocompetent patients, with 89 percent sensitivity and 99 percent specificity. Elevated IgM antibodies will remain detectable for two to three months after acute infection. IgG testing is less useful because it only indicates previous infection and immunity ${ }^{[6]}$.

\section{Conclusion:-}

Anemia with reticulocytopenia in patients with hemoglobinopathies and in immunocompromised hosts (e.g. patients with AIDS, transplant recipients) should alert the clinician to the possibility of parvovirus B19 infection. Tests are available to confirm the diagnosis. Management includes packed red cell transfusions and, in cases of immunocompromised patients, administration of intravenous immunoglobulin ${ }^{[7]}$. 


\section{Reference: -}

1. Jordan, Jeanne, Hirsch, Martin, Edward, Morven, Bloom, Allyson, 2014, Microbiology, epidemiology, and pathogenesis of parvovirus B19 infection. Uptodate. The George Washington University.

2. Villanueva. AnaV. Chandrasekar, P.H. 1999. Parvovirus B19 in a patient with sickle cell crisis, Division of Infectious Diseases, Wayne State University School of Medicine.

3. Jordan, Jeanne, Hirsch, Martin, Edward, Morven, Bloom, Allyson, 2013, Clinical manifestations and pathogenesis of human parvovirus B19 infection.Uptodate.The George Washington University.

4. Scarier, Stanley, Mentzer, William, Landaw, Stephan. 2013, Acquired pure red cell aplasia. Uptodate. Stanford University School of Medicine.

5. Obeid E, Obeid (2011), molecular and serological assessment of parvovirus B19 infections among sickle cell anemia patients, Department of microbiology, University of Dammam.

6. T, JESSICA .V, BRIAN. HODGE, JOSHUA .2007. Clinical Presentations of Parvovirus B19 Infection. Travis Air Force Base, California. Uniformed Services University of the Health Sciences, Bethesda, Maryland. Andrews Air Force Base, Maryland.

7. Setúbal, Sérgio .Adelmo H.D, Gabriel. Jussara P. Nascimentoe Solange A. Oliveira .2000. Aplastic crisis caused by parvovirus B19 in an adult patient with sickle-cell disease. Revista da SociedadeBrasileira de MedicinaTropical. 